\title{
Effect of patient age on blood product transfusion after cardiac surgery
}

\author{
Niv Ad, MD, Paul S. Massimiano, MD, Nelson A. Burton, MD, Linda Halpin, MSN, RN, \\ Graciela Pritchard, BS, Deborah J. Shuman, BS, and Sari D. Holmes, PhD
}

\section{ABSTRACT}

Objective: Blood product transfusion after cardiac surgery is associated with increased morbidity and mortality. Transfusion thresholds are often lower for the elderly, despite the lack of clinical evidence for this practice. This study examined the role of age as a predictor for blood transfusion.

Methods: A total of 1898 patients were identified who had nonemergent cardiac surgery, between January 2007 and August 2013, without intra-aortic balloon pumps or reoperations, and with short $(<24$ hours) intensive care unit stays (age $\geq 75$ years; $n=239$ ). Patients age $\geq 75$ years were propensity-score matched to those age $<75$ years to balance covariates, resulting in 222 patients per group. Analyses of the matched sample examined age as a continuous variable, scaled in 5 -year increments.

Results: After matching, covariates were balanced between older and younger patients. Older age significantly predicted postoperative (odds ratio $=1.39$, $P=.028$ ), but not intraoperative (odds ratio $=0.96, P=.559$ ), blood transfusion. Older age predicted longer length of stay $(\mathrm{B}=0.21, P<.001)$, even after adjustment for blood product transfusion $(\mathrm{B}=0.20, P<.001)$. As expected, older age was a significant predictor for poorer survival, even with multivariate adjustment (hazard ratio $=1.34, P=.042$ ).

Conclusions: In patients with a routine postoperative course, older age was associated with more postoperative blood transfusion. Older age was also predictive of longer length of stay and poorer survival, even after accounting for clinical factors. Continued study into effects of transfusion, particularly in the elderly, should be directed toward hospital transfusion protocols to optimize perioperative care. (J Thorac Cardiovasc Surg 2015;150:209-14)

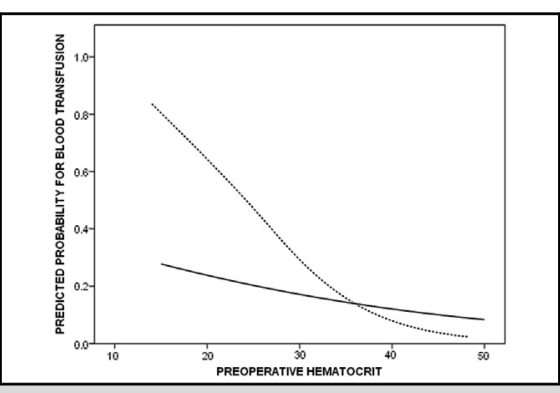

The figure shows spline curves demonstrating the relationship of preoperative hematocrit with odds for blood transfusion, for ages $\geq 75$ years (dashed line) and ages $<75$ years (solid line) in the matched sample.

\section{Central Message}

For routine cardiac surgery, older patient age was a robust predictor for postoperative blood product transfusion and was predictive of longer length of stay and poorer survival.

\section{Perspective}

This study demonstrates that patient age is associated with a significant surgeon bias regarding blood transfusion thresholds without proven clinical merit. Future studies should focus on specific blood transfusion protocols for older patients to maximize the appropriateness of blood transfusion after cardiac surgery.

See Editorial Commentary page 214
Cardiac surgery accounts for a substantial proportion of surgical procedures in which blood and blood products are transfused. ${ }^{1,2}$ The risks associated with blood transfusion are difficult to ascribe to clearly delineated risk factors. ${ }^{3}$ However, cardiac surgery that involves transfusion is associated with a higher risk of infection and ischemic

\footnotetext{
From Cardiac Surgery Research, Inova Heart and Vascular Institute, Falls Church, Va. Read at the 40th Annual Meeting of The Western Thoracic Surgical Association, Dana Point, California, June 25-28, 2014.

Received for publication June 25, 2014; revisions received March 9, 2015; accepted for publication March 15, 2015; available ahead of print April 18, 2015.

Address for reprints: Niv Ad, MD, Inova Heart and Vascular Institute, 3300 Gallows

Rd, Ste 3100, Falls Church, VA 22042 (E-mail: niv.ad@inova.org). $0022-5223 / \$ 36.00$

Copyright (c) 2015 by The American Association for Thoracic Surgery http://dx.doi.org/10.1016/j.jtcvs.2015.03.022
}

outcomes, ${ }^{2,4}$ longer length of stay, ${ }^{5}$ and increased perioperative and long-term morbidity and mortality ${ }^{6,7}$ compared with cardiac procedures without transfusion. Recent studies have found that cardiac surgery programs that develop and adhere to a blood conservation protocol succeed in reducing the incidence of blood transfusion, improving outcomes, and minimizing health care costs. ${ }^{8-10}$

In general, when postoperative hemoglobin levels are $\leq 10 \mathrm{~g} / \mathrm{dL}$, elderly patients are more likely than younger patients to receive transfusion. ${ }^{9,11}$ Transfusion thresholds are often lower (ie, transfusion occurs at higher hemoglobin levels) in the elderly, despite the scarcity of clinical evidence to support this practice. ${ }^{9}$ Few published studies have examined blood transfusion in elderly (age $>75$ years) patients undergoing cardiac surgery, and the effects of transfusion after cardiac surgery in a specific subset 


\section{Abbreviations and Acronyms \\ $\mathrm{CI}=$ confidence interval \\ EuroSCORE $=$ European System for Cardiac \\ Operative Risk Evaluation \\ $\mathrm{HR} \quad=$ hazard ratio \\ $\mathrm{OR} \quad=$ odds ratio}

of elderly patients have not been previously described. In this study, we examined the role of age as a predictor for blood transfusion and the effects of age on postoperative outcomes in elderly patients undergoing cardiac surgery.

\section{METHODS}

A total of 1898 consecutive patients who had undergone nonemergent cardiac surgery between January 2007 and August 2013 were identified. These patients did not have placement of an intra-aortic balloon pump or reoperation for bleeding or any other indication, and all had short ( $<24$ hours) stays in the intensive care unit. Most patients (64\%) who met these criteria underwent coronary artery bypass graft surgery, either alone or in combination with another cardiac surgical procedure. Of this sample, 239 patients $(13 \%)$ were age $\geq 75$ years.

This study was approved by our local institutional review board (nos. 06.022 and 12.055) and was granted a waiver of consent. All procedures followed were in accordance with the ethical standards of the responsible committee on human experimentation (institutional and national) and with the Helsinki Declaration of 1975, as revised in 2000. Data were obtained from our local Society of Thoracic Surgeons database and were merged with survival and clinical information collected at our institution. Data on long-term survival were obtained from the National Death Index (closing date: December 31, 2010), the Social Security Death Index (closing date: January 31, 2013), and our institutional follow-up program (ongoing).

\section{Blood Transfusion Protocol}

In 2007, we implemented a rigorous, multidisciplinary, criteria-driven algorithm for blood transfusion in cardiac surgery patients at our center. Cardiopulmonary bypass techniques, anesthesia, management of perioperative bleeding, and strict indications for blood transfusion were modified as part of this protocol. Transfusion was approved only by an attending cardiac surgeon in symptomatic patients, and specific criteria were developed for intraoperative and postoperative transfusion (Figure 1). Regardless of this protocol, transfusion can be ordered by the attending surgeon if it is deemed clinically justified.

\section{Statistical Analyses}

All analyses were conducted with SPSS, Version 17.0 (SPSS Inc, Chicago, Ill) and R 2.10.1 (R Foundation for Statistical Computing, Vienna, Austria). A 2-sided $P$ was computed. Data are presented as mean $\pm \mathrm{SD}$, median (interquartile range), or frequency (percentage). Comparisons involving dichotomous dependent variables were evaluated with $\chi^{2}$ analysis, Fisher's exact test, or logistic regression; comparisons involving continuous dependent variables were evaluated with Student's $t$ test, the Mann-Whitney $U$ test, or linear regression.

To improve balance between the 2 groups, patients age $<75$ years were matched by propensity score to patients age $\geq 75$ years, using the MatchIt package for R (R Foundation for Statistical Computing, Vienna, Austria). The propensity for age $\geq 75$ years was estimated with a logistic model, using the following covariates: gender; body mass index; ejection fraction;
EuroSCORE II (European System for Cardiac Operative Risk Evaluation); preoperative hematocrit; status (urgent or elective); hypertension; surgery (isolated coronary artery bypass graft or other); chronic pulmonary disease; diabetes; peripheral vascular disease; and cerebrovascular disease. Patients were matched based on propensity score, using a caliper of 0.25 propensity-score SD. After matching, 222 patients remained in each age group, and good covariate balance was achieved between the 2 age groups (Figure 2).

Outcome analyses were conducted exclusively on the matched sample, and age was examined as a continuous variable (scaled by 5 years), unless otherwise noted. Logistic regressions were performed to evaluate the effect of age on the risk for intraoperative and postoperative blood transfusion, as well as on perioperative outcomes. Univariate logistic regressions were run separately within each matched age group to evaluate the effect of preoperative hematocrit on the probability of perioperative blood transfusion and to visualize these relationships using spline curves. In addition, multivariate logistic regression analysis was used to formally test for interaction of age and preoperative hematocrit before the analysis of separate age groups. Cox proportional hazards modeling was conducted to examine the effects of age as a continuous variable (scaled by 5 years) and blood transfusion on long-term survival.

\section{RESULTS}

Mean age for the unmatched sample was $61.4 \pm 11.6$ years, and most patients $(79 \%)$ were men. Before propensity-score matching, the prevalence of preoperative comorbid conditions, including hypertension, congestive heart failure, history of stroke, and peripheral vascular disease, was higher for patients age $\geq 75$ years (Table 1 ). No difference by age group was found for type of cardiac surgery procedure. After propensity-score matching, all preoperative characteristics of patients age $\geq 75$ years $(n=222)$ were similar to those of patients age $<75$ years $(n=222)$, except age (Table 2). All results that follow were found within the propensity scorematched sample $(\mathrm{N}=444)$.

Blood products were transfused in 55 patients $(12 \%)$. Intraoperative transfusion only was used in 35 patients, postoperative transfusion only in 15 patients, and intraoperative and postoperative transfusion in 5 patients. The incidence of Society of Thoracic Surgeons-defined complications was low in this matched sample. Such complications included: 2 patients with pneumonia $(0.5 \%) ; 2$ with a stroke and/or transient ischemic attack $(0.5 \%) ; 2$ who died within 30 days $(0.5 \%) ; 4$ with major morbidity or mortality $(0.9 \%)$; and 33 with readmissions within 30 days $(7 \%)$.

\section{Age and Outcomes}

Age as a continuous variable did not predict intraoperative transfusion (odds ratio $[\mathrm{OR}]=0.96,95 \%$ confidence interval $[\mathrm{CI}], 0.85-1.10, P=.559)$, but age was a significant predictor for postoperative transfusion $(\mathrm{OR}=1.39,95 \%$ CI, 1.04-1.87, $P=.028$ ). For every 5-year increase in patient age, the odds of postoperative transfusion were $39 \%$ greater. Age remained a significant predictor for postoperative transfusion $(\mathrm{OR}=1.40,95 \% \mathrm{CI}, 1.04-1.88, P=.027)$ after adjustment for preoperative hematocrit. 


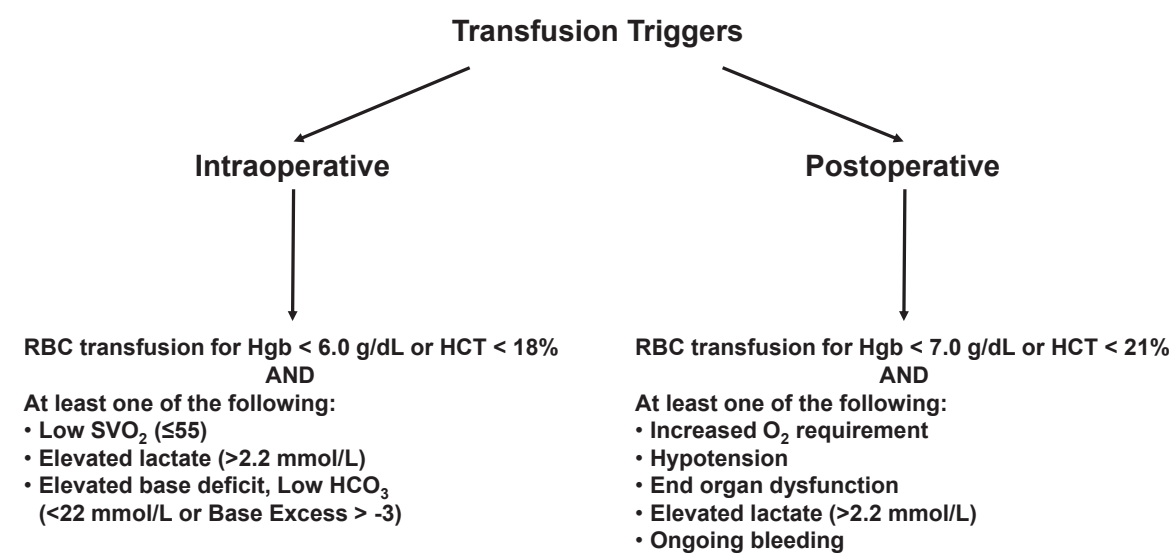

FIGURE 1. The figure shows a diagram of the transfusion protocol implemented at our cardiac surgery center. $R B C$, Red blood cell; $H g b$, hemoglobin; $\mathrm{HCT}$, hematocrit; $\mathrm{SVO}_{2}$, venous oxygen saturation; $\mathrm{HCO}_{3}$, blood bicarbonate; $\mathrm{O}_{2}$, oxygen.

For double robustness, adjustment was made for all clinical covariates included in the propensity model, but it did not eliminate the predictive effect of age as a continuous variable on postoperative transfusion $(\mathrm{OR}=1.40,95 \%$ CI, $1.04-1.89, P=.029)$. Older age as a continuous variable was significantly correlated with more units of postoperative blood products $\left(r_{s}=0.10, P=.039\right)$.

Finally, an examination of the interaction of preoperative hematocrit and age on transfusion found hematocrit $(\mathrm{OR}=1.39, P=.03)$, age $(\mathrm{OR}=1.27, P=.006)$, and the interaction term $(\mathrm{OR}=0.99, P=.005)$ to be significantly predictive of perioperative blood product transfusion.

\section{Distribution of Propensity Scores}

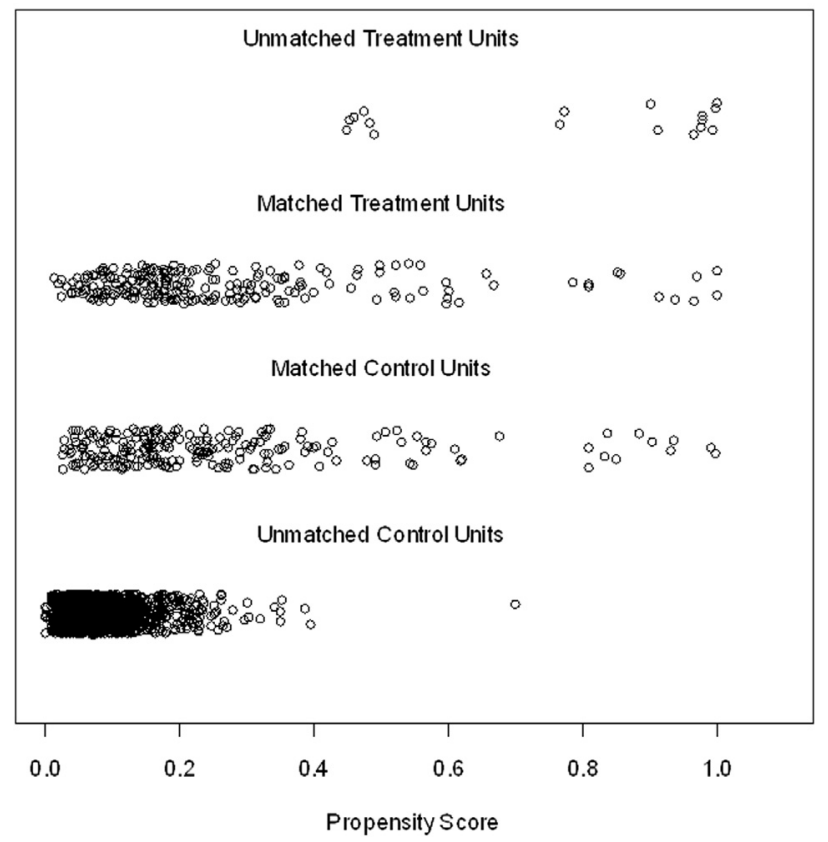

FIGURE 2. The figure shows the distribution of propensity scores for control (age $<75$ years) and treatment (age $\geq 75$ years) units.
Specifically, the relationship between preoperative hematocrit and the odds for receiving any perioperative blood product transfusion was significant among patients age $\geq 75$ years $(\mathrm{OR}=0.86,95 \% \mathrm{CI}, 0.78-0.94, P=.001)$ but not for those age $<75$ years $(\mathrm{OR}=0.96,95 \% \mathrm{CI}, 0.89$ $1.03, P=.277$; Figure 3 ). For patients age $\geq 75$ years, a $1 \%$ increase in preoperative hematocrit was associated with a $14 \%$ reduction in odds for blood product transfusion.

The incidence of stroke and/or transient ischemic attack, pneumonia, major morbidity or mortality, and readmission within 30 days was not significantly predicted by age as a continuous variable (Table 3 ). However, older age was predictive of longer total length of stay in days $(B=0.21$, $P<.001)$. This finding remained significant after multivariate analysis $(\mathrm{B}=0.20, P<.001)$. Furthermore, addition of blood product transfusion did not remove the effect of age on length of stay $(\mathrm{B}=0.20, P<.001)$, but transfusion was also significantly associated with longer length of stay $(\mathrm{B}=1.30, P<.001)$.

\section{Survival}

Long-term follow-up for survival was captured over a mean follow-up period of $35.1 \pm 20.4$ months. As expected, Cox proportional hazards regression revealed that age as a continuous variable was a significant predictor of poorer survival (hazard ratio $[\mathrm{HR}]=1.43,95 \% \mathrm{CI}=1.07-1.92, P=.016$ ). After adjustment for the covariates from the propensityscore model, age remained a significant predictor of poorer survival $(\mathrm{HR}=1.34,95 \% \mathrm{CI}=1.01-1.77, P=.042)$.

\section{DISCUSSION}

This study focused specifically on age as a discriminator for perioperative transfusion of blood and blood products in patients who underwent cardiac surgery and had a routine and relatively smooth course afterward. We found age to be a robust predictor for blood product transfusion after surgery. Older age as a continuous variable was associated with 
TABLE 1. Preoperative and operative characteristics by age group before matching

\begin{tabular}{lccr}
\hline \multicolumn{1}{c}{ Characteristic } & $\begin{array}{c}\text { Age }<\mathbf{7 5} \mathbf{y} \\
(\mathbf{n}=\mathbf{1 6 5 9})\end{array}$ & $\begin{array}{c}\text { Age } \geq \mathbf{7 5} \mathbf{y} \\
(\mathbf{n}=\mathbf{2 3 9})\end{array}$ & $\boldsymbol{P}$ value \\
\hline Age $(\mathrm{y})$ & $58.8 \pm 10.0$ & $78.8 \pm 3.2$ & $<.001$ \\
Gender, female & $329(20)$ & $64(27)$ & .013 \\
Diabetes mellitus & $447(27)$ & $62(26)$ & .744 \\
Body mass index $\left(\mathrm{kg} / \mathrm{m}^{2}\right)$ & $29.0 \pm 8.3$ & $26.7 \pm 4.2$ & $<.001$ \\
Hypertension & $1122(68)$ & $204(85)$ & $<.001$ \\
Congestive heart failure & $130(8)$ & $40(17)$ & $<.001$ \\
Ejection fraction $(\%)$ & $57.9 \pm 7.7$ & $58.5 \pm 7.1$ & .284 \\
Previous CVA & $68(4)$ & $20(8)$ & .003 \\
Cerebrovascular disease & $152(9)$ & $41(17)$ & $<.001$ \\
Chronic pulmonary disease & $229(14)$ & $49(21)$ & .006 \\
Creatinine $>$ 2 mg/dL & $15(1)$ & $4(2)$ & .286 \\
Peripheral vascular disease & $106(6)$ & $27(11)$ & .005 \\
Urgent status & $561(34)$ & $63(26)$ & .022 \\
Preoperative hematocrit & $40.1 \pm 4.5$ & $38.3 \pm 4.5$ & $<.001$ \\
EuroSCORE II & $1.3 \pm 1.3$ & $3.3 \pm 3.2$ & $<.001$ \\
Type of surgery & & & \\
$\quad$ CABG & $1064(64)$ & $148(62)$ & .506 \\
Valve surgery & $516(31)$ & $84(35)$ & .209 \\
$\quad$ Surgical ablation & $107(6)$ & $18(8)$ & .528 \\
CPB time (min) & $102.6 \pm 37.2$ & $95.8 \pm 30.2$ & .003 \\
\hline Data & &
\end{tabular}

Data are presented as mean \pm SD or frequency $(\%)$, unless otherwise indicated. The categories for type of surgery are not mutually exclusive. CVA, Cerebrovascular accident; EuroSCORE, European System for Cardiac Operative Risk Evaluation; $C A B G$, coronary artery bypass grafting; $C P B$, cardiopulmonary bypass.

greater odds of receiving a blood product transfusion after surgery, which in previous studies was associated with a greater likelihood of complications, regardless of age. ${ }^{2,4-7}$ In our sample, older age was significantly associated with longer length of stay and poorer survival after discharge. Older age was associated with greater odds for transfusion; the relationship between hematocrit before surgery and

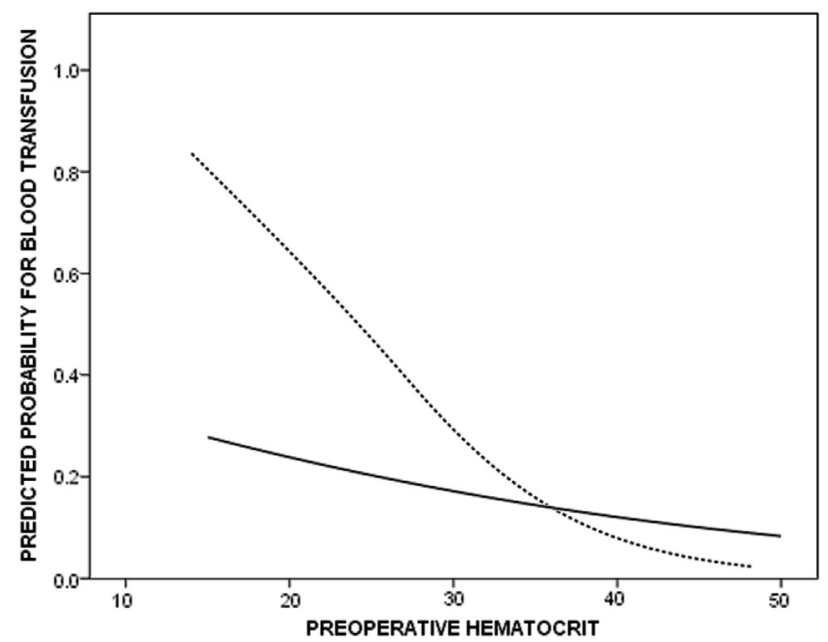

FIGURE 3. The figure shows spline curves demonstrating the relationship of preoperative hematocrit with odds for blood transfusion, for ages $\geq 75$ years (dashed line) and ages $<75$ years (solid line) in the matched sample.
TABLE 2. Preoperative and operative characteristics by age group after matching

\begin{tabular}{lccr}
\hline \multicolumn{1}{c}{ Characteristic } & $\begin{array}{c}\text { Age }<\mathbf{7 5} \mathbf{y} \\
(\mathbf{n}=\mathbf{2 2 2})\end{array}$ & $\begin{array}{c}\text { Age } \geq \mathbf{7 5} \mathbf{y} \\
(\mathbf{n}=\mathbf{2 2 2})\end{array}$ & $\boldsymbol{P}$ value \\
\hline Age $(\mathrm{y})$ & $61.0 \pm 11.0$ & $78.6 \pm 3.1$ & $<.001$ \\
Gender, female & $60(27)$ & $54(24)$ & .515 \\
Diabetes mellitus & $57(26)$ & $56(25)$ & .913 \\
Body mass index $\left(\mathrm{kg} / \mathrm{m}^{2}\right)$ & $26.3 \pm 3.8$ & $26.7 \pm 4.1$ & .325 \\
Hypertension & $184(83)$ & $187(84)$ & .701 \\
Congestive heart failure & $24(11)$ & $31(14)$ & .313 \\
Ejection fraction $(\%)$ & $58.9 \pm 9.1$ & $58.7 \pm 6.9$ & .772 \\
Previous CVA & $15(7)$ & $14(6)$ & .848 \\
Cerebrovascular disease & $37(17)$ & $31(14)$ & .429 \\
Chronic pulmonary disease & $38(17)$ & $46(21)$ & .332 \\
Creatinine $>2$ mg/dL & $10(5)$ & $4(2)$ & .103 \\
Peripheral vascular disease & $22(10)$ & $24(11)$ & .755 \\
Urgent status & $61(28)$ & $61(28)$ & $>.999$ \\
Preoperative hematocrit & $38.1 \pm 4.9$ & $38.4 \pm 4.5$ & .534 \\
EuroSCORE II & $2.6 \pm 2.6$ & $2.8 \pm 2.5$ & .393 \\
Type of surgery & & & \\
$\quad$ CABG & $135(61)$ & $139(63)$ & .696 \\
Valve surgery & $84(38)$ & $77(35)$ & .490 \\
$\quad$ Surgical ablation & $13(6)$ & $13(6)$ & $>.999$ \\
CPB time (min) & $109.5 \pm 43.3$ & $94.6 \pm 28.9$ & $<.001$ \\
\hline Dar & &
\end{tabular}

Data are presented as mean $\pm \mathrm{SD}$, or frequency $(\%)$, unless otherwise indicated. The categories for type of surgery are not mutually exclusive. CVA, Cerebrovascular accident; EuroSCORE, European System for Cardiac Operative Risk Evaluation; $C P B$, cardiopulmonary bypass; $C A B G$, coronary artery bypass grafting.

the odds for receiving any perioperative blood product transfusion was significant among only patients age $\geq 75$ years, and not for those age $<75$ years.

Intraoperative transfusion of blood and blood products is primarily intended to maintain or restore tissue oxygenation. Cardiac surgical patients are at risk of severe bleeding, and some patients are at risk of hemorrhagic shock. Consensus is lacking, however, on the hematocrit level at which the benefit of transfusion in cardiac surgery patients outweighs the risks. The World Health Organization defines anemia as a hemoglobin level of $<13 \mathrm{~g} / \mathrm{dL}$ for adult men and $<12 \mathrm{~g} / \mathrm{dL}$ for nonpregnant adult women. ${ }^{12}$ Several other organizations have issued guidelines for perioperative blood transfusion. ${ }^{13-20}$

TABLE 3. Perioperative outcomes by age as a continuous variable, scaled in 5-year increments

\begin{tabular}{lccr}
\hline \multicolumn{1}{c}{ Outcome } & OR & $\mathbf{9 5} \%$ CI & $\boldsymbol{P}$ value \\
\hline Length of stay (d) & 0.21 & $0.11-0.30$ & $<.001$ \\
Permanent stroke or TIA & 0.94 & $0.55-1.61$ & .828 \\
Pneumonia & 1.22 & $0.56-2.66$ & .623 \\
Blood transfusion & & & \\
$\quad$ Intraoperative & 0.96 & $0.85-1.10$ & .559 \\
$\quad$ Postoperative & 1.39 & $1.04-1.87$ & .028 \\
Mortality and major morbidity & 1.68 & $0.76-3.72$ & .200 \\
Readmission within $<30 \mathrm{~d}$ & 0.99 & $0.85-1.15$ & .578 \\
\hline
\end{tabular}

Data are presented as B coefficient from linear regression for length of stay only. The blood transfusion categories are not mutually exclusive. $O R$, Odds ratio; $C I$, confidence interval; TIA, transient ischemic attack. 
Despite these guidelines, the rate at which transfusion is used for cardiac surgery varies widely among hospitals, clinical trials, and cardiac intensive care units. ${ }^{21-23}$ Recommendations are based primarily on expert opinion rather than established evidence. ${ }^{7,16-18}$ Several reports support the use of a more restrictive transfusion strategy (ie, at lower hemoglobin levels). The Transfusion Requirements After Cardiac Surgery (TRACS) study ${ }^{24}$ compared a liberal blood transfusion strategy (hematocrit $\geq 30 \%$ ) with a restrictive strategy (hematocrit $\geq 24 \%$ ). The restrictive strategy was not inferior to the liberal strategy in terms of postoperative ( $\leq 30$-day) morbidity and mortality. In another study evaluating transfusion thresholds, patients undergoing coronary artery bypass grafting were randomly assigned to receive transfusion at hemoglobin thresholds of $<8 \mathrm{~g} / \mathrm{dL}$ and $<9 \mathrm{~g} / \mathrm{dL}$. No differences were found in morbidity, mortality, or self-assessed fatigue or anemia. ${ }^{25}$

The lack of clarity on transfusion thresholds complicates the decision regarding when to transfuse elderly patients who have had cardiac surgery and may put these patients at greater risk, compared with younger patients, for complications associated with transfusion. In general, given similar hemoglobin levels of $\leq 10 \mathrm{~g} / \mathrm{dL}$, the tendency among surgeons to give postoperative blood transfusion is greater with elderly versus younger patients, ${ }^{9,11}$ despite the lack of evidence supporting this practice. Possibly, surgeons perceive older patients as being frailer simply because of their age, and not because of other, more objective determinants of vulnerability.

Given the lack of consensus on the hematocrit level at which transfusion should be employed, elderly patients remain particularly at risk of the complications that attend blood transfusion, especially given that they are more likely than younger patients to receive transfusion at a given hemoglobin level. The results of our study add to the body of evidence showing an increased risk associated with transfusion in elderly patients undergoing cardiac surgery. They also lend further support to a more restrictive approach to transfusion during and after cardiac surgery, particularly in elderly patients.

\section{Limitations}

The results of this study provide evidence that patient age is a factor in the transfusion decision-making process. Owing to the complex nature of the clinical elements involved in blood product transfusion, these results do not provide confirmation of causality, but they can provide directions for future research. In addition, the rigorous nature of our institutional blood protocol may affect the generalizability of these findings to other centers. However, without a rigorous protocol for transfusion, the independent impact of patient age on transfusion may be stronger.

\section{CONCLUSIONS}

In patients who experience a routine course immediately after cardiac surgery, older age was found to be associated with a greater likelihood of blood and blood product transfusion after surgery. In addition, older age was found to be predictive of longer length of stay and poorer survival, even after adjustment for clinical factors. Continued study of transfusion effects, particularly in the elderly, should be directed toward more-sophisticated transfusion protocols to optimize perioperative care.

\section{Conflict of Interest Statement}

Dr Niv Ad is a consultant and a member of the speaker's bureau for Medtronic, Inc and AtriCure, Inc. All other authors have nothing to disclose with regard to commercial support.

\section{References}

1. US Department of Health and Human Services. 2011 National Blood Collection and Utilization Survey Report. Available at: http://www.hhs.gov/ash/bloodsafety/ 2011-nbcus.pdf. Accessed February 2, 2015.

2. Horvath KA, Acker MA, Chang H, Bagiella E, Smith PK, Iribarne A, et al. Blood transfusion and infection after cardiac surgery. Ann Thorac Surg. 2013;95: 2194-201

3. Loor G, Rajeswaran J, Li L, Sabik JF III, Blackstone EH, McCrae KR, et al. The least of 3 evils: exposure to red blood cell transfusion, anemia, or both? J Thorac Cardiovasc Surg. 2013;146:1480-7.e6.

4. Murphy GJ, Reeves BC, Rogers CA, Rizvi SI, Culliford L, Angelini GD Increased mortality, postoperative morbidity, and cost after red blood cell transfusion in patients having cardiac surgery. Circulation. 2007;116:2544-52.

5. Galas FR, Almeida JP, Fukushima JT, Osawa EA, Nakamura RE, Silva CM, et al. Blood transfusion in cardiac surgery is a risk factor for increased hospital length of stay in adult patients. J Cardiothorac Surg. 2013;8:54.

6. Engoren MC, Habib RH, Zacharias A, Schwann TA, Riordan CJ, Durham SJ. Effect of blood transfusion on long-term survival after cardiac operation. Ann Thorac Surg. 2002; 74:1180-6.

7. Bhaskar B, Dulhunty J, Mullany DV, Fraser JF. Impact of blood product transfusion on short and long-term survival after cardiac surgery: more evidence. Ann Thorac Surg. 2012;94:460-7.

8. LaPar DJ, Crosby IK, Ailawadi G, Ad N, Choi E, Spiess BD, et al. Blood product conservation is associated with improved outcomes and reduced costs after cardiac surgery. J Thorac Cardiovasc Surg. 2013;145:796-803; discussion 803-4.

9. Brown CH IV, Savage WJ, Masear CG, Walston JD, Tian J, Colantuoni E, et al Odds of transfusion for older adults compared to younger adults undergoing surgery. Anesth Analg. 2014;118:1168-78.

10. Yaffee DW, Smith DE III, Ursomanno PA, Hill FT, Galloway AC, DeAnda A, et al. Management of blood transfusion in aortic valve surgery: impact of a blood conservation strategy. Ann Thorac Surg. 2014;97:95-101.

11. Sherwood MW, Wang Y, Curtis JP, Peterson ED, Rao SV. Patterns and outcomes of red blood cell transfusion in patients undergoing percutaneous coronary intervention. JAMA. 2014;311:836-43

12. World Health Organization. Haemoglobin Concentrations for the Diagnosis of Anaemia and Assessment of severity. Vitamin and Mineral Nutrition Information System. Geneva, Switzerland: World Health Organization; 2011.

13. National Institutes of Health. Perioperative red cell transfusion. National Institutes of Health consensus development conference. Transfus Med Rev. 1989;3 63-8.

14. American College of Physicians. Practice strategies for elective red blood cell transfusion. Ann Intern Med. 1992;116:403-6.

15. American College of Anesthesiologists. Practice guidelines for blood componen therapy: a report by the American Society of Anesthesiologists task force on blood component therapy. Anesthesiology. 1996;84:732-47.

16. Murphy MF, Wallington TB, Kelsey P, Boulton F, Bruce M, Cohen H, et al. Guidelines for the clinical use of red cell transfusions. Br J Haematol. 2001 113:24-31. 
17. National Health and Medical Research Council, Australasian Society of Blood Transfusion (NHMRC/ASBT). Clinical Practice Guidelines: Appropriate Use of Red Blood Cells. Canberra, Australia: NHMRC/ASBT; 2001.

18. Canadian Medical Association. Guidelines for red blood cell and plasma transfusion for adults and children. Can Med Assoc J. 1997;156(Suppl 11): S1-25.

19. Napolitano LM, Kurek S, Luchette FA, Corwin HL, Barie PS, Tisherman SA, et al. Clinical practice guideline: red blood cell transfusion in adult trauma and critical care. Crit Care Med. 2009;37:3124-57.

20. Society of Thoracic Surgeons Blood Conservation Guideline Task ForceFerraris VA, Brown JR, Despotis GJ, Hammon JW, Reece TB, Saha SP, et al. 2011 update to the Society of Thoracic Surgeons and the Society of Cardiovascular Anesthesiologists blood conservation clinical practice guidelines. Ann Thorac Surg. 2011;91:944-82.

21. Wu WC, Rathore SS, Wang Y, Radford MJ, Krumholz HM. Blood transfusion in elderly patients with acute myocardial infarction. N Engl J Med. 2001;345: 1230-6.
22. Hebert PC, Wells G, Tweeddale M, Martin C, Marshall J, Pham B, et al. Does transfusion practice affect mortality in critically ill patients? Transfusion requirements in critical care (TRICC) investigators and the Canadian Critical Care Trials Group. Am J Respir Crit Care Med. 1997;155:1618-23.

23. Chesebro JH, Knatterud G, Roberts R, Borer J, Cohen LS, Dalen J, et al. Thrombolysis in Myocardial Infarction (TIMI) trial, phase I: a comparison between intravenous tissue plasminogen activator and intravenous streptokinase. Clinical findings through hospital discharge. Circulation. 1987;76:142-54.

24. Hajjar LA, Vincent JL, Galas FR, Nakamura RE, Silva CM, Santos MH, et al. Transfusion requirements after cardiac surgery: the TRACS randomized controlled trial. JAMA. 2010;304:1559-67.

25. Bracey AW, Radovancevic R, Riggs SA, Houston S, Cozart H, Vaughn WK, et al. Lowering the hemoglobin threshold for transfusion in coronary artery bypass procedures: effect on patient outcome. Transfusion. 1999;39:1070-7.

Key Words: Transfusion, elderly, cardiac surgery

\section{EDITORIAL COMMENTARY}

\section{Does the "retrospectoscope" help define best practices in transfusion?}

John W. Hammon, MD

See related article on pages 209-14.

In the past several years, there has been an almost irresistible push by cardiac surgeons, anesthesiologists, critical care physicians, and blood bank personnel to lower the number of transfusions of whole blood and blood products for patients undergoing cardiac surgery. A mechanism for achieving this goal has been to adjust one indication for transfusion from a serum hemoglobin of less than $10 \mathrm{~g} / \mathrm{dL}$ to less than $7 \mathrm{~g} / \mathrm{dL} .{ }^{1}$ Because of the lack of hard evidence to support this recommendation, the variation in hospital practice in the United States has been extraordinary, ranging from $5 \%$ adoption to more than $90 \%$ among patients undergoing coronary artery bypass grafting surgery. ${ }^{2}$ There have

From the Department of Cardiothoracic Surgery, Wake Forest, School of Medicine, Winston-Salem, NC.

Disclosures: Author has nothing to disclose with regard to commercial support.

Received for publication March 26, 2015; accepted for publication March 28, 2015; available ahead of print April 29, 2015.

Address for reprints: John W. Hammon, MD, Department of Cardiothoracic Surgery, Wake Forest University School of Medicine, Medical Center Blvd, WinstonSalem, NC 27157-1096 (E-mail: jhammon@wfubmc.edu).

DOI of original article: http://dx.doi.org/10.1016/j.jtcvs.2015.03.022

J Thorac Cardiovasc Surg 2015;150:214-5

$0022-5223 / \$ 36.00$

Copyright (c) 2015 by The American Association for Thoracic Surgery

http://dx.doi.org/10.1016/j.jtcvs.2015.03.052 been many attempts to test the effects of this change, including the study by Ad and colleagues ${ }^{3}$ in this issue of the Journal.

With a retrospective analysis of 1898 consecutive patients undergoing nonemergency cardiac surgery between 2007 and 2013, Ad and colleagues $^{3}$ sought to ascertain the transfusion status of these patients

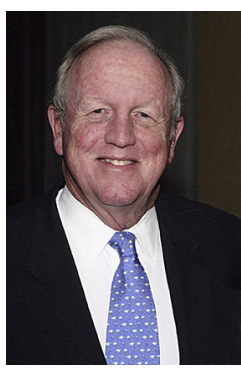
and to find out the effect of transfusion on 222 patients aged 75 or older. This project was driven by evidence that older patients require more transfusions. Their hospital had instituted a rigorous blood conservation protocol, as recommended by the Society of Thoracic Surgeons guideline; how would this change effect outcomes? Because the groups were unequal in size, and the older patients were at significantly greater risk, Ad and colleagues ${ }^{3}$ were obliged to use propensity-matching analysis to balance the groups and studied patients older and younger than 75 years.

They found that older age predicted postoperative blood transfusion, longer hospital stay, and poorer survival, even with the new more restrictive blood conservation protocol. It would seem logical that the new protocol failed to reduce blood use in the older group, and this may have led to poorer survival. We must, however, take a closer look at 